\title{
LAS EXEQUIAS A MARIANA DE AUSTRIA EN LOS VIRREINATOS AMERICANOS, TRASLATIO Y METÁFORAS EN VUELO*
}

\author{
JUDITH FARRÉ VIDAL \\ Consejo Superior de Investigaciones Científicas - CCHS \\ judith.farre@csic.es
}

$\mathrm{E}$ 1 águila como metáfora asociada al poder tiene un recorrido muy amplio que abarca desde las culturas mesoamericanas hasta la tradición clásica. Dentro de este prolijo marco de interpretación, es también una de las estrategias fundamentales en la configuración simbólica del elogio a Mariana como reina de la Casa de Austria. Si bien la metáfora de la aurora y la luna (Farré Vidal, 2003: I, 267-294) ocuparon un lugar preeminente para el encomio a las reinas de los Austrias en sus etapas de juventud, pues son metáforas de fertilidad que equiparan la sucesión dinástica y la renovación de los ciclos en la naturaleza, la asimilación simbólica con el águila desempeñó un papel predominante en las etapas más maduras de sus reinados. A partir de edades más adultas y, sobre todo, en las etapas más cercanas a la muerte, el águila cumple un importante papel, tal y como ha estudiado Rodríguez Moya en la tradición jesuita de redacción de las exequias femeninas (2013: 61). Y en el caso específico de Mariana, como reina regente hasta la mayoría de edad de Carlos II, es especialmente significativo. La singular y novedosa condición de Mariana, que pasó de ser consorte a ejercer de reina regente, la convierte en un interesante caso de estudio (Oliván, 2006). Esa especial condición, unida a la coyuntura con la que Perú y Nueva España afrontaban en 1697 la crisis de la monarquía, el reinado de Carlos II, el incierto panorama ante la sucesión y el cambio de siglo, son las razones para este estudio comparado sobre las exequias americanas a Mariana de Austria. Mi objetivo no es el análisis

* Este texto forma parte del proyecto de investigación «En los bordes del archivo II: escrituras efímeras desde los virreinatos de Indias» (FFI2015-63878-C2-2-P) financiado por el Ministerio de Ciencia, Innovación y Universidades de España $<$ http://www.enlosbordesdelarchivo.com $>$. Una primera versión de este trabajo se presentó en el VII Seminario Internacional de Historia Comparada-Red de Sucesión «Mariana de Austria: gobierno, piedad y representación en la Monarquía de España (16491696)», celebrado en la Universidad Autónoma de Madrid (Madrid, 27-28 de febrero de 2018). 
concreto de la iconografía de los túmulos, sino trazar una comparación entre los procesos de localización y adaptación del ritual político de la muerte llevados a cabo en los dos virreinatos, su traslatio a partir de la formulación central en la metrópoli y dentro de un marco de redes cosmopolitas en una cultura global.

Los Llantos imperiales de Melpomene regia, seguramente más pomposos en el título que en su ejecución, resumen las ceremonias que tuvieron lugar el 12 de julio en el Colegio Imperial de Madrid por la muerte de «la ínclita Reina Señora Doña Mariana de Austria, madre de don Carlos II, Rey de las Españas, Emperador de América. Hija, nieta, bisnieta y continuada descendiente de los emperadores de Alemania. Esposa que fue meritísima del señor Rey don Felipe IV». El título del impreso madrileño apunta el eje vector con el que trazar los procesos de localización a los que se someterá el ritual de las exequias en lugares alejados como Lima y México, al tiempo que destaca su papel de madre de Carlos II, que encaja dentro de un linaje y una genealogía imperial. Esta entronización dinástica es por un lado necesaria para destacar la figura de Carlos II como rey y, por otro lado, a pesar del luto por la pérdida, garantizar la continuidad y la estabilidad de la monarquía.

Esa idea de permanencia es la que desarrollarán los jeroglíficos del túmulo madrileño, que plantearán el elogio a la vida de Mariana en cuatro etapas cíclicas: la vida, la muerte, el sepulcro y la salvación, y que irán trazando la alegoría de los distintos emblemas y jeroglíficos (Llantos imperiales de Melpomene regia, f. 69r). De todo el diseño iconográfico destacan dos aves: el águila y la paloma, símbolos de la vertiente política y espiritual, a la vez que signos de vida y muerte, respectivamente. Según la Iconología de Ripa, la definición de la paloma tiene una clara proyección espiritual que encaja muy bien en la terna compuesta por Felipe IV, Mariana y Carlos II:

el símbolo del Espíritu Santo, tercera persona de la Santísima Trinidad y vínculo del amor entre el padre y el hijo, por mediación del cual se comunica la Divina Justicia a todos aquellos príncipes que gobiernan el Mundo. Se hace dicha paloma blanca y resplandeciente, porque dichas cualidades son de aquellas que consideramos visuales y nobilísimas (Ripa, 1996: II, 9).

La paloma aparece en uno de los emblemas que se describen en los Llantos imperiales de Madrid. En él se representa la ciudad de Dios, tal y como la pinta san Juan en su Apocalipsis, con su puerta central abierta para recibir una paloma blanca, «ideada piadosamente en ella la alma justa de nuestra Reina, al ir volando a entrar en el cielo» (Llantos imperiales de Melpomene regia, f. 90v). En su pico llevaba un mote con la inscripción: «Sin miedo de eclipses voy / a vivir dichosa en una / ciudad sin sol y sin luna» (f. 91r). La explicación de la imagen alude al eclipse lunar que precedió a la muerte de la reina madre, pero 
también a su aceptación serena y piadosa de la muerte tras el largo proceso de enfermedad que tuvo que afrontar. Además, con el emblema su alma se asocia a una paloma, símbolo también del Espíritu Santo, y queda sellada la continuidad dinástica de una monarquía espiritualista como la de los Austrias.

El eclipse como indicio de grandeza y la paloma como signo de espiritualidad pueden interpretarse en términos similares. Como ejemplo de esta complementariedad simbólica, el Romance que explica la correspondencia que tuvo la muerte de la Reyna Madre Ntra. Sra., por el eclipse de luna, con la de Philipo Quarto, su esposo, que la pronosticó un cometa, un manuscrito que se conserva en la Biblioteca Nacional de España. El romance lo firma Melchor de Guzmán Osorio Dávila Manrique de Zúñiga, XII marqués de Astorga y virrey y capitán general de Galicia, aunque bajo el título de «un cortesano y fiel criado». Del texto, una poesía laudatoria de circunstancias con escaso valor literario, puede destacarse la elaboración simbólica que equipara a ambos monarcas y los indicios sobrenaturales que son testimonio de su majestad extraordinaria:

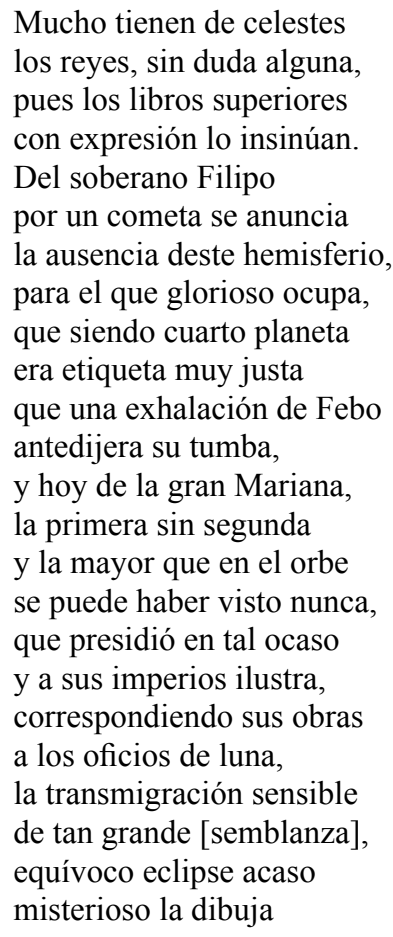

(Romance que explica la correspondencia, f. 1r). 
La lectura sobrenatural del eclipse como presagio de la muerte de Mariana, que en el anterior romance se equipara con el cometa que precedió la muerte de Felipe IV, también aparece en el impreso de las exequias limeñas, la Funeral pompa y solemnidad..., donde se describe un emblema a propósito del eclipse:

Pintose un cielo nublado y a un lado el Sol eclipsado y al otro la Luna, y la Reina en medio muerta, con muchas estrellas enlutadas y abajo esta copla: Muere la Aurora y se enlutan / Cielo, Sol, Luna y Estrellas, / que reina el eclipse en todos, / si en todos el dolor reina (Funeral pompa, f. 114v).

La muerte de la reina madre, más allá de contener los elogios habituales, significaba una de las últimas oportunidades para incluir algún miembro de los Austrias españoles en el santoral. Lo ha estudiado Gómez Vozmediano, que al tratar el expediente eclesiástico informativo en torno al proceso de beatificación de Mariana, recoge la siguiente noticia: «que la noche que llevaron el cuerpo de la reina al Escorial, según contaron los que la acompañaron, iba sobre la litera todo el camino una paloma blanca dando vueltas, cosa que causó igual admiración» (2005: 570). El proceso de beatificación no fue más allá, aunque se generaron algunas noticias curiosas. Dentro de la documentación conservada destaca la nota procedente de Puerto Rico, que aseguraba que un águila real estuvo sobrevolando la catedral mientras se estaban celebrando las exequias fúnebres. Dicha información se adjuntó rápidamente al expediente en curso (2005: 571).

Las noticias sobre el intento de beatificación son más bien escasas, pero llama la atención que tengan un mayor protagonismo en lugares alejados de la corte, como sucede en las exequias americanas, donde la cualidad de santa se incorporó rápida y claramente al elogio fúnebre. Por ejemplo, en la Funeral pompa y solemnidad de Lima se preguntaba el relator:

qué haría este inevitable poder en los pechos de unos vasallos tan leales auxiliando la destreza de sus sagradas consonancias con las memorias de una Reina grande, justa y, si se disculpa el conocimiento de una piedad enternecida, santa (f. 55v).

También José Vidal de Figueroa, en el Sermón en los funerales celebrados en la catedral de México, se planteaba cómo predicar las «obsequiosas honras» de Mariana ya que:

morir o acabar esta vida mortal para pasar a la eterna con aclamaciones de santa son dos puntos distintos, que piden estilos diferentes y afectos encontrados: morir y dejar el Reino en desconsuelo y tristeza pide estilo fúnebre con que provocar a llanto $[\ldots]$ pero salir de esta vida mortal con aclamaciones de santa pide estilo festivo, alegre y panegírico para dejar muy consolado a su reino por haber subido a más sublime corona (Sermón en las honras, f. 58r). 
La paloma también se representa en algunos emblemas que se describen en las exequias de Lima. Por ejemplo, en uno de ellos se destaca el vuelo ascendente, que puede interpretarse como un signo expreso de espiritualidad: «una nave, ya sumergidos los árboles en las turbadas ondas y de las gavias volaba una paloma hacia las nubes, ceñido todo este rótulo: Alliditur Navis, non laditur Avis» (f. 34r); en otro ejemplo, esta idea se refuerza con la serenidad que aporta la rama de olivo en el pico: «Y sobre este globo volaba una cándida paloma llevando en el pico una rama de oliva, anuncio de las serenidades, con tal ingenio entregada al movimiento de las alas, que solo un pie estribaba en el rótulo, que decía: Volabo \& requiescam» (f. 40r).

Si bien, como vemos, la imagen de la paloma y las cualidades de serenidad y espiritualidad que se le asocian tienen una presencia importante en el diseño de los túmulos americanos, el elemento central de todas las composiciones es el águila, símbolo de la preponderancia de la esfera política. Así se marca también en los Llantos imperiales publicados en Madrid:

Estaba pintado el cadáver de la Reina nuestra Señora en su féretro y recostado sobre una imperial águila de muy sobresaliente grandeza, que afianzando el pie del féretro en las garras y las alas en ademán de vuelo extendido y como viajada a la altura, semejaba llevarla al cielo (Llantos imperiales, f. 83r-v).

En correspondencia, como traslatio del modelo madrileño, uno de los elementos centrales en las exequias limeñas era un «águila que coronada y empuñando un cetro con la garra tendía heroicamente las alas» (f. 31v). Es interesante notar cómo en la propuesta peruana del túmulo, el águila aparece como símbolo en numerosas ocasiones, unas veces como metáfora de la reina y otras como representación de su alma. Esta segunda lectura, que recuerda el episodio antes mencionado del águila sobrevolando la catedral de Puerto Rico durante la misa funeral por Mariana, es una de la más interesantes. Por ejemplo,

Bien espera esta feliz Ciudad de Lima mejorado el favor, más seguro el amparo, que gozaba al advertir coronada de estrellas esta Real Águila, que sube en alas de sus virtudes, desde el incendio de este Túmulo, para que si la muerte nos privó de una prudente Reina que gobierne, nos dé el cielo un astro favorable que nos alumbre (Funeral pompa, f. 10r).

Hacia el final del impreso limeño se corrobora esta idea de subida a los cielos y se apunta, como colofón, la idea de apoteosis:

Por eso te ha inaugurado el cielo con el imperial manto de sus eternos resplandores, en lugar de la efímera púrpura que arrebató el mundo de tus hombros. Por eso, pues Águila Real asciendes por los funestos humos de la pira a aumentarle al empíreo, 
la numerosa suerte de sus astros, sin que la notoriedad de tu naturaleza obligase a la veneración de los peruanos al recuerdo de la fabulosa apoteosis (Funeral pompa, f. 163r).

Por su parte, la metáfora de la mujer-águila sobre la que se edifica la simbología del túmulo de la catedral de México se construye a partir del ejemplo del túmulo del emperador Carlos V (Cervantes de Salazar, Túmulo imperial a las exequias del invictísmo Carlos V, México: 1560), que se presenta como argumento de autoridad:

El Águila es símbolo de fortaleza en letras humanas y divinas, baste por todas la dibujada en el Real túmulo del invencible Carlos quinto con esta inscripción, insignias de los fuertes, en que afianzo una Mitra docta, leer Mujer Águila, en lugar de mujer fuerte. Así se equivocan o se unen los dos autores con bisagra de oro, que forjaron a nuestra dormida emperatriz-águila mujer fuerte-águila del sermón ( $L a$ imperial águila renovada, s.p.).

A pesar de la grandilocuente elaboración simbólica que supone el emblema del águila, las exequias de 1696 en Madrid fueron más bien discretas y austeras en su ejecución material. Como ya han estudiado Osorio (2004), Allo Manero (1989, 2004) y Jouve Martín (2016), la pragmática de los lutos de 1693 que regulaba el gasto fue una de las razones por las que las honras fúnebres moderaron los recursos. Así, por ejemplo, la condesa de Berlips le escribía al elector Palatino algunos detalles del funeral celebrado en Madrid. En una carta puede leerse lo siguiente:

el ataúd salió precedido de los Grandes a caballo, con hachas en las manos, y tres religiosos de cada Orden, también con hachas. Detrás del féretro iban tres damas en burros y la camarera mayor en una mula. Al pasar la última puerta se rompieron las andas, accidente que ha debido ocurrir otras veces, y la ceremonia se retrasó tres cuartos de hora (Jouvé, 2016: 196).

Esa austeridad también aplica para el caso novohispano, tal y como se desprende del comentario de Antonio Robles en el Diario de sucesos notables: «Honras de la reina en Santo Domingo. Lunes 10 celebró la Inquisición en Santo Domingo las honras de la Reina; el túmulo fue más lucido que el de la Catedral; cantaron misa las religiones en las capillas y los responsos en el túmulo» (Robles, 1946: III, 54). Llama la atención que las exequias celebradas por los dominicos fueran más lucidas que las auspiciadas por la catedral, donde tiene su sede el obispo. Un caso muy distinto es el de las celebraciones en Lima. Aunque en la relación impresa de las exequias limeñas se llegó a reproducir la cédula real y los rigurosos deseos de contención en el gasto, se aprecia como primera novedad que todos los gastos corrieron a cuenta del virrey: 
No permitió en aquel grave congreso su generosísimo ánimo, afligido con la pérdida de nuestra Reina y cuidadoso con las atenciones que mandaba nuestro Rey y Señor se tuviesen a su Real hacienda, aunque estas solo se coartaban a los lutos de los Ministros, que excediesen en su pecho a las piedades de príncipe religioso, a las fervorosas lealtades de vasallo, y así dijo que todos los gastos del real túmulo quería que corriesen por su cuenta y que se fabricase con toda la magnificencia posible a expensas de su caudal, sin que se tocase en efecto o ramo alguno de la Real Hacienda (Funeral pompa, f. 20r-v).

El factor económico se convierte así en una de las diferencias fundamentales entre las exequias organizadas en ambos virreinatos. Las diferencias en el gasto tienen que ver con la distinta situación sociopolítica de cada virreinato. Por un lado, en Nueva España el arzobispo Juan de Ortega y Montañés fue nombrado virrey interino del 27 de febrero hasta el 18 de diciembre de 1696. Su cargo era en sustitución del cuestionado conde de Galve que, enfermo y muy desgastado en el gobierno tras la revuelta de 1692, presentó varias veces su renuncia, que fue finalmente admitida en septiembre de 1695. Sus últimos años de gobierno estuvieron estigmatizados por el tumulto de 1692 y contrastan con su primera fase en el cargo, que estuvo marcada por la victoria en la isla de Santo Domingo ante los franceses y sus embestidas contra los piratas ingleses (Gutiérrez Lorenzo, 1993: 121). Tras estos últimos años grises del mandato del conde de Galve, 1696, el año de celebración de las exequias de Mariana de Austria, fue para Nueva España un año de transición, marcado por el gobierno de un obispo-virrey interino que no asumió grandes proyectos, ni buscaba reconocimiento alguno en la corte madrileña. Además, otro aspecto que se debe tener en cuenta es que la corte novohispana también era consciente de la temporalidad del gobierno, por lo que ninguna de las partes del entramado palaciego debía estar interesada en sufragar un fasto en estas condiciones.

Por el contrario, el virrey en Lima desde 1689 era el III conde de la Monclova, grande de España de primera clase, comendador de la Zarza en la Orden de Caballeros de Alcántara, consejero de Guerra y gentilhombre de Cámara de Carlos II. Sirvió en las guerras de Flandes, Sicilia, Cataluña y Portugal (Rubio Mañé, 2005: I, 257). Se trataba de un noble de primera clase que, además, contaba con un ilustre pasado militar. La prueba más palpable y notoria de ello fue la batalla de las dunas de Dunquerque, en 1658, en la que perdió el brazo derecho que sustituyó por una prótesis de plata. La huella del valor de sus gestas militares se equipara a su generosidad y magnanimidad. Dicha ecuación se hace visible en uno de los emblemas de las exequias de Lima, donde se llegó a pintar su brazo acompañado de un soneto: 
Este brillante túmulo erigido / a expensas desta mano generosa, / que de la luz del Austria es mariposa / prendiendo en sus lealtades lo encendido. / Es del águila real luciente nido, / en que anima la vida más gloriosa, / pues Fénix siendo de virtud dichosa, / opone eternidades al olvido (Funeral pompa, f. 154v).

El conde de la Monclova había sido anteriormente virrey en Nueva España, por lo que su nombramiento como virrey en Lima debe verse como otro ascenso tras la labor desempeñada en México. En Perú heredó una hacienda pública muy disminuida tras la crisis del trigo de 1687, el último terremoto y los conflictos internacionales que debía financiar la Corona. A pesar del estado general de crisis económica, la capital limeña ostentaba su hegemonía como emporio comercial del Pacífico. Podían alternarse etapas de crisis y florecimiento, pero la capital del virreinato peruano insistía en proyectar una imagen sofisticada de la ciudad «con toda suerte de acontecimientos festivos, especialmente las entradas reales pensadas para reafirmar la lealtad al régimen monárquico» (Holguera, 2017: 93).

En este ambiente general, en el que el virreinato peruano consolidaba su madurez, emergía la figura particular del experimentado conde de la Monclova. Su personalidad, más allá de su prestigio como militar y gobernante, puede también medirse a partir de las posesiones de las que se rodeó, que le presentan como un coleccionista culto que proclamaba «su condición distinguida, transformándolo en indiscutido director del gusto», $\mathrm{y}$ «cuyas preferencias estéticas» fueron tomadas como signos de modernidad e «imitadas por algunos integrantes de la élite urbana» (Holguera, 2017: 93). Esta dimensión coleccionista es especialmente significativa en un momento de reconstrucción de la ciudad tras los últimos temblores.

Así pues, la distinta personalidad y situación de ambos virreyes marca en 1696 una diferencia fundamental entre ambos virreinatos, que conduce también a distintos planteamientos en la organización de las exequias a Mariana. Aunque antes de analizar las especiales circunstancias que rodean las exequias limeñas es necesario presentar los rasgos que comparten con las novohispanas. Además de la simbología de las aves que señalaba en líneas anteriores, fundamentalmente en lo que respecta al águila, cabe destacar la coincidencia de presentar a mujeres bíblicas, modelos de fortaleza, para diseñar el imaginario del elogio: Judith como asunto del sermón novohispano y Raquel en la simbología del túmulo peruano.

Por ejemplo, José Vidal de Figueroa declara que la «inteligencia del texto» novohispano se ha de entender "solo del tiempo que después de Judith viuda gobernó a Israel y que en todo este tiempo no hubo quien inquietara al reino» (f. 60r) y destaca la regencia como principal asunto para la alegoría:

conforme a esta explicación acomodaré con más rigor a la letra el Mulierem fortem quis inveniet a la Reina Nuestra Señora, quien hallará una mujer fuerte que sepa gobernar no solo un reino unido en doce tribus, como la madre de Salomón; ni 
una familia y casa como la madre del Nacianceno, sino una dilatada monarquía dividida en muchos reinos, sin faltar a las horas de oración mental con Dios y otros ejercicios espirituales en que se ocupaba para su mayor perfección, pues cese ya Salomón de preguntar si habrá una mujer tan fuerte como su madre, que yo respondo mostrándole la reina Nuestra Señora Doña Mariana de Austria, que supo gobernar no solo un reino, sino una monarquía con tanto acierto y paz como le enseñó la experiencia (Sermón en las honras, f. 61v).

Por su parte, la relación limeña expone sobre el túmulo que

El pensamiento fue imitar en todas las circunstancias de su construcción aquel célebre y primero sepulcro que advierten las Sagradas Letras labró Jacob en una bien dispuesta pirámide a la hermosísima Raquel, estribando en doce robustas piedras que servían de basas y significaban las doce tribus, y en este real mausoleo hicieron representación de doce reinos que se explicaron más en la elegancia de doce simulacros (Funeral pompa, f. 30r).

Junto a la simbología más esencial del ritual político de la muerte, que consiste en trazar con emblemas el elogio simbólico y político del rey muerto, cabe destacar como singulares los procesos de localización y adaptación del ceremonial llevados a cabo en los dos virreinatos. En ambos casos, la traslatio señala los beneficios obtenidos por cada virreinato en tiempos de Mariana, aspecto que explicaría que anteriormente se hubiera destacado el periodo de gobierno y regencia por encima de las vertientes de Mariana como madre y viuda. En la ciudad de México, José Vidal de Figueroa resume en el sermón el sentir general de estas estrategias de localización y declara cómo la retórica exige un discurso general de alabanza hacia la monarquía, necesario para la unidad del imperio, que más tarde pasará al «compendioso epítome» de cada reino:

Hasta aquí ha procedido el discurso en lo general de la monarquía, porque no era bien que nos dividiéramos en el sentimiento cuando estuvimos tan unidos todos los reinos a su amor, como sujetos a su obediencia el tiempo de su gobierno; pero será preciso que este reino declare algo de lo mucho que le debió, y porque es tanto, que no cabe en la brevedad de este sermón, redúzcolo a este compendioso epítome (Sermón en las honras, f. 65v).

Por su parte, en Nueva España se señala, en primer lugar, la consagración de la catedral de México, dedicada a la reina madre en la celebración de su natalicio del 22 de diciembre de 1667, por lo que se loa que haya sido la madre del primer rey de España allí coronado «con la solemnidad que pide la escritura Sagrada» (Sermón en las honras, f. 66r). En segundo lugar, se destaca la limosna de 10.000 pesos para fundar la misión evangélica en las islas Marianas y redimir las almas 
que «eran pobres e inútiles y estériles para el comercio humano» y estaban al paso de México a las islas Filipinas (Sermón en las honras, ff. 67r y 68r).

Más interesante es nuevamente el caso de Lima, donde puede apreciarse una dimensión apoteósica propia. Junto a la mayor ostentación que se proyecta en Lima respecto a Madrid y México, cabe apuntar que sus exequias se plantean recrear proximidad en la imagen de la lejana reina que no se conoció en vida:

Su real vida nos hizo dichosos con su gobierno; su feliz muerte nos deja envidiados con su ejemplo: nos favoreció desde el trono, nos ilustra desde el sepulcro (Funeral ротра, f. $7 \mathrm{v})$.

$[\ldots]$

Los que por la suerte de las remotas regiones que habitamos no conocimos a nuestra felicísima Reina, la alcanzamos a ver en la altura del suntuoso túmulo que nos negó el infortunio de la distancia en su vida, nos concedió la industria del poder en su muerte (Funeral pompa, f. 8r-v).

Los anteriores ejemplos tratan de proximidad y fastuosidad. El gasto, el artificio y el homenaje a la reina difunta se interpretan en clave política: la altura del túmulo es símbolo de la grandeza de Mariana. Pero, junto a la grandeza política, en el homenaje caben también el amor y la lealtad:

Fue ingeniosa grandeza del corazón que dedicó tanto gasto a las últimas resoluciones del arte, porque no fuesen demostraciones menores que la causa del sentimiento, y así depositó su amor y lealtad en las cuatro pirámides que como abrasadas mariposas rodeaban el lucimiento del túmulo (Funeral pompa, f. 41r).

El virrey asumió todos los gastos de las exequias, la impresión del voluminoso impreso que daba cuenta de ellas, e incluso la reconstrucción de la catedral donde se edificó el túmulo. De todo ello se desprende el empeño personal del virrey en su ejecución:

Siendo alma de todas las disposiciones (que importaban a la Majestad de las Exequias y convenían a aquel generoso ardimiento con que siempre ha atendido al cumplimiento de los reales servicios), consagró a la Augustísima memoria de la difunta reina la fábrica suntuosa, la funesta máquina de un túmulo, por cuya magnífica arquitectura parece que lidiaron el Amor y el poder (Funeral pompa, f. 3v).

El III conde de la Monclova se presenta como «padre destos reinos más que virrey» (Funeral pompa, f. 3r). También queda claro en la relación limeña que su papel no fue solo el de mecenas, que quiso ser también «ejecutor» de sus órdenes y asistir también con «la pericia de su voluntad», puesto que mientras duró la obra:

le tuvo en continuo movimiento desde el palacio a la iglesia, ya alentando a los artífices, ya mejorando las labores, ya dirigiendo los pinceles, ya corrigiendo los diseños, sin que excusase ejercicio que conducía a la brevedad y grandeza de la 
obra, y a aquella parte de consuelo que suele librar en liberales impensas el amor lastimado, procurando con la elegancia del artificio arrebatarle a la muerte aquella generosísima vida que ya no la deja ser aliento la mortalidad (Funeral pompa, f. 4v).

El tono paternalista con que se presenta el virrey y su intervención en el diseño y ejecución del túmulo resultan excepcionales si se comparan con, por ejemplo, las exequias que tuvieron lugar en Nueva España. En el caso de Lima, una ciudad que debía estar ruinosa por los últimos terremotos, la construcción del túmulo, así como la reconstrucción de la catedral, son dos ejemplos claros de la voluntad particular del III conde de la Monclova, hombre de Estado y noble de primera clase, de seguir ejerciendo su valor y lealtad por la monarquía. Al mismo tiempo, desde una perspectiva general, los desvelos del virrey apuntan a la proyección de la imagen de la ciudad como una urbe pujante y sofisticada, en un momento de crisis generalizada. Las exequias son un acto de amor y lealtad hacia la monarquía y la propia ciudad de Lima:

El desconsuelo de todos, efectos fueron del antiguo reconocimiento del natural amor que como mayorazgo de la fe española ha vinculado en este reino la lealtad, siempre ha corrido con estimación, pero ahora ha manifestado su ley, apurando todo el valor de sus quilates, en el fuego del crisol que labró la fidelidad en el pecho del Excelentísimo Señor Conde de la Monclova, donde, sin que le pueda apagar el venenoso soplo de la envidia, vive inextinguible aquella llama del amor a sus reyes (Funeral pompa, f. 160v).

La voluntad del virrey y la lealtad de Perú resultan patentes en las fastuosas exequias celebradas en Lima, en las que el virreinato peruano proyecta además una majestuosa imagen que contrasta con las discretas celebraciones llevadas a cabo en la catedral novohispana. La celebración de estos funerales también es testimonio de una decisión e interés particular del virrey, quien evidencia fastuosas disposiciones a pesar de la austeridad y la contención en el gasto que se pedía en la cédula real.

Como conclusión, se puede apuntar que este tipo de representaciones luctuosas del poder real en el contexto colonial siguen una estricta etiqueta, bien marcada desde la metrópoli. Se construyen también a partir de unas lealtades dinásticas bien definidas. A pesar de todo, en su traslatio al contexto americano, es necesario considerar también el especial contexto que marcan las estructuras locales y sus circunstancias particulares. Una cuestión que, además, a finales del siglo XVII es fundamental, en tanto que el cambio de siglo traerá consigo la llegada de los Borbones para sustituir a los Austrias como dinastía reinante. En este contexto de crisis generalizada, desde la perspectiva americana, también es importante tener en cuenta el progresivo protagonismo del virreinato peruano en las rutas comerciales del Pacífico. 
En este caso, las diferencias entre los contextos de los dos virreinatos determinan dos formas diferentes de celebrar las exequias a Mariana de Austria, que a su vez reflejan distintos objetivos. Como vimos, la transitoriedad de un obispo-virrey interino, sin ambiciones en la corte madrileña y sin un proyecto local y de futuro definido, marcó que en Nueva España la celebración siguiera la austeridad marcada desde Madrid y se limitara a las retóricas simbólicas propias del elogio fúnebre.

En el caso del Perú, a pesar de la crisis, deben considerarse dos factores distintivos. Por un lado, la necesidad de proyectar y exhibir una imagen próspera y sofisticada, acorde con su pujante hegemonía como emporio comercial del Pacífico. Por otro lado, la personalidad y especial impronta del III conde de la Monclova. La implicación y la personal huella que imprime el virrey en el diseño y realización de las exequias, además de buscar establecer una posición en la corte madrileña, le confieren un protagonismo en el luto que excede los límites exigidos por el protocolo: corre con todos los gastos y se implica activamente en su diseño y ejecución.

El gasto y el gusto del virrey son patentes en la ostentación pública de las exequias y es interesante trazar coincidencias con las pautas que rigen su colección particular, cuyo inventario fue resuelto ante el escribano Francisco Sánchez Becerra en 1705 (Holguera, 2017: 96), donde se combinan: muestras de imágenes de culto consolidadas en el acervo popular criollo («dos lienzos de Nuestra Señora de Guadalupe grande y otro pequeño» [2017: 98]); y, a modo de galería de hombres ilustres, varios ejemplos aparentemente irreconciliables, pero muestra de su tiempo: «un lienzo de cuerpo entero del Rey Don Carlos II con su marco dorado»; «otro del rey Nuestro Señor, Dios guarde, Don Felipe quinto con marco dorado» (2017: 98); «once lienzos pequeños de la casa de Francia» y «un cuadrito pequeño de una madame francesa» (2017: 99); «otros dos lienzos de medio cuerpo con su marco dorado de los señores reyes Don Carlos II y Mariana»; «otro del señor don Juan de Austria» y «otro del señor Cardenal Portocarrero» (2017: 99).

La colección particular del virrey, como un gabinete de curiosidades, atesoraba una muestra de retratos en la que conviven Austrias y Borbones y donde quedan plasmadas las tensiones políticas de finales del siglo XVII. El III conde de la Monclova, hombre piadoso y hombre de estado, se sirve del programa alegórico de las exequias a Mariana para proyectarse públicamente como «padre destos reinos más que virrey». El luto por Mariana es una cuestión de estado, una oportunidad con la que sellar el compromiso del virreinato ante la monarquía, pero es también una ocasión con la que el virrey desea proyectar en la ciudad de Lima su cercanía familiar con la reina madre, fruto de sus relaciones en la corte madrileña. 


\section{BIBLIOGRAFÍA}

Allo Manero, María Adelaida (1989). «Aportación al estudio de las exequias reales en Hispanoamérica. La influencia sevillana en algunos túmulos limeños y mejicanos». Anuario del Departamento de Historia y Teoría del Arte, 1, pp. 121-138.

Allo Manero, María Adelaida y Juan Francisco Esteban Llorente (2004). «El estudio de las exequias reales de la monarquía hispana: siglos XVI, XVII y XVIII». Artigrama, 19, pp. 39-94.

Chocano Mena, Magdalena (1999). «Poder y trascendencia: La muerte del rey desde la perspectiva novohispana (ss. XVI y XVII)». Jahrbuch für Geschichte Lateinamerikas (Anuario de Historia de América Latina), 36, pp. 83-104.

ESQUERRA, Matías de (1697). La imperial águila renovada por la inmortalidad de su nombre en la fuente de las lágrimas que tributó a su muerte... esae mexicana Corte... para que descanse... doña Mariana de Austria cuyas fúnebres pompas executó... don Juan de Ortega Montañez obispo de Valladolid... descríbelas el hermano... México: Imprenta de Iuan Ioseph Guillena Carrascoso [Biblioteca Nacional de España, 2/67.474].

Farré VIDAL, Judith (2003). Dramaturgia y espectáculo del elogio. Loas completas de Agustin de Salazar y Torres. Kassel: Reichenberger.

Gómez Vozmediano, Miguel (2005). «En olor a santidad. La fallida beatificación de la reina Mariana de Austria». En María Victoria López Cordón y Francisco Fernández Izquierdo (eds.), Actas de la VIII Reunión Científica de la Fundación Española de Historia Moderna (Madrid, 2-4 de junio de 2004). Madrid: Fundación Española de Historia Moderna, I, pp. 555-576.

Gutiérrez Lorenzo, María Pilar (1993). De la corte de Castilla al virreinato de México: el Conde de Galve (1653-1697). Guadalajara: Diputación Provincial.

GuZmán Osorio Dávila Manrique de ZúÑIGa, Melchor de (1697). Romance que explica la correspondencia entre muerte de la Reyna Madre [Mariana de Austria]..., por el eclipse de luna, con la de Philipo Quarto, su esposo, que la pronosticó un cometa [Biblioteca Nacional de España, ms. 12.955/18].

Holguera Cabrera, Antonio (2017). «La galería pictótica del III conde de la Monclova (1690-1705)». Cuadernos de Arte de la Universidad de Granada, 48, pp. 91-104.

Jouve MarTín, José Ramón (2016). «Reina, madre y águila del imperio: las exequias por Mariana de Austria en Lima (1697)». En Catherine Poupeney Hart, Sebastián Ferrero y Juan C. Godenzzi (eds.), El Perú en su historia: fracturas y persistencias. Paris: Éditions Le Manuscrit, pp. 195-232.

Olvín, Laura (2006). Mariana de Austria. Imagen, poder y diplomacia de una reina cortesana. Madrid: Universidad Complutense de Madrid.

Osorio, Alejandra (2004). «The king in Lima. Simulacra, Ritual and Rule in Seventeenth-Century Peru». Hispanic American Historical Review, 84.3, pp. 447-474.

PINTO, Jorge de (1697). Llantos imperiales de melpomene regia: llora la muerte de la inclita reyna señora doña Maria Ana de Austria, madre de don Carlos II. Madrid: Antonio de Zafra [Biblioteca Nacional de España, 2/63.621].

RIPA, Cesare (1996). Iconología. Madrid: Akal.

Robles, Antonio de (1946). Diario de sucesos notables. Ciudad de México: Porrúa. 
Rodríguez Moya, Inmaculada (2013). «La mujer-águila y la imagen de la reina en los virreinatos americanos». Quiroga: Revista de Patrimonio Iberoamericano, 4, pp. 58-75.

Romero GonzÁlez de Villalobos, Bernardo (1697). Funeral pompa, y solemnidad en las exequias a la muerte de la cathólica y serenissma Reyna Madre D. Mariana de Austria ... que celebro en la Iglesia metropolitana de Lima... Melchor de Portocarrero... Lima: Joseph de Contreras [Biblioteca Nacional de España, 2/68.251].

Rubio Mañé, José Ignacio (2005). El Virreinato: Orígenes y jurisdicciones, y dinámica social de los virreyes. Ciudad de México: Fondo de Cultura Económica.

Vidal de Figueroa, José (1696). Sermón en las honras de la reyna Nuestra señora Doña Mariana de Austria [...]. Mexico: s.l. British Library Online <https://n9.cl/2dh7> [Consulta: 24/01/2020].

Recibido: 27/01/2020

Aceptado: 03/03/2020 


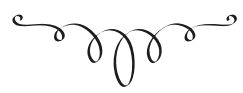

\section{Las eXequias a Mariana de Austria en los VirReinatos americanos, TRASLATIO Y METÁFORAS EN VUELO}

RESUMEN: La singular y novedosa condición de Mariana de Austria, que pasó de ser consorte a ejercer de reina regente, la convierte en un interesante caso de estudio. Esa especial condición, unida a la coyuntura con la que Perú y Nueva España afrontaban en 1697 la crisis de la monarquía, el reinado de Carlos II, el incierto panorama ante la sucesión y el cambio de siglo, son las razones para este estudio comparado sobre las exequias americanas a Mariana de Austria. Mi objetivo no es el análisis concreto de la iconografía de los túmulos, sino trazar una comparación entre los procesos de localización y adaptación del ritual político de la muerte llevados a cabo en los dos virreinatos, su traslatio a partir de la formulación central en la metrópoli y dentro de un marco de redes cosmopolitas en una cultura global.

Palabras Clave: Mariana de Austria, exequias reales, virreinatos americanos, metáforas, rituales políticos.

\section{American Funeral Rites for Mariana of Austria in the AMERICAN VICEROYALTIES, TRASLATIO AND FLY METAPHORS}

ABSTRACT: The unique and novel situation of Mariana of Austria, who went from being Consort to becoming Queen Regent, the particular circumstances in which Peru and New Spain faced the crisis of the monarchy in 1697, along with the uncertain panorama over the succession, the reign of Charles II and the turn of the century, are the cornerstones of my analysis of the American funeral rites of Mariana of Austria. My objective is not the specific analysis of the iconography of the tombs, but to draw a comparison between the processes of localization and adaptation of the political ritual of death carried out in the two viceroyalties, their traslatio from their central formulation in the metropolis and within a framework of cosmopolitan networks within a global culture.

Key Words: Mariana de Austria, Funeral Rites, American Viceroyalties, Metaphors, Political Rituals. 